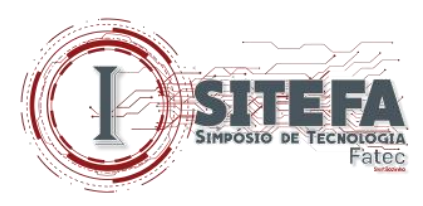

\title{
ANÁLISE DE FALHA EM DENTE DE ENGRENAGEM
}

\section{FAILURE ANALYSIS OF GEAR TOOTH}

\author{
Prof. Dr. Maurício Angeloni - mauricio.angeloni@fatec.sp.gov.br \\ Faculdade de Tecnologia (FATEC) - Sertãozinho - São Paulo - Brasil \\ Sérgio Murilo Correia de Oliveira Junior - sergio.oliveira23@fatec.sp.gov.br \\ Alexandre Ribeiro Camilo - alexandre.camilo@fatec.sp.gov.br \\ Tecnólogos em Manutenção Industrial \\ Faculdade de Tecnologia (FATEC) - Sertãozinho - São Paulo - Brasil
}

\begin{abstract}
RESUMO
Nos últimos anos grandes mudanças provocadas tanto pela aplicação de normas, ambientais e de segurança, mais rígidas, como pela crescente demanda de um mercado cada vez mais globalizado e competitivo, o que leva os materiais utilizados na fabricação de peças e componentes a condições cada vez mais extremas de utilização. Com exigências cada vez maiores, devido a constante busca pelo o aumento de produtividade, surge a necessidade de uma melhor caracterização desses materiais, principalmente no que se refere à transição do comportamento dúctil-frágil, de modo a garantir a segurança e a confiabilidade das peças e componentes fabricados, evitando, assim, possíveis falhas catastróficas. Neste trabalho, objetivou-se determinar a possível causa raiz de uma fratura num dente de engrenagem, por meio de ensaios como análise química realizada via espectrometria de emissão óptica por centelhamento, análise macroestrutural e perfil de microdureza. Como resultado, obteve-se não só a caracterização do material, concentradores de tensão no processo de fabricação, como também a faixa de microdureza entre a superfície do material ao centro por meio da medição em vickers.
\end{abstract}

Palavras-chave: Fadiga. Dente de Engrenagem. Análise de Falha. Dureza. Propriedades Mecânicas.

\begin{abstract}
In recent years, major changes have been caused by the application of stricter environmental, safety and security standards, as well as by the growing demand for an increasingly globalized and competitive market, which leads to the materials used to manufacture parts and components under ever changing conditions more extreme use. With increasing demands, due to the constant search for the increase of productivity, the need arises for a better characterization of these materials, especially with regard to the transition of the ductilefragile behavior, in order to guarantee the safety and the reliability of the pieces and manufactured components, thus avoiding possible catastrophic failures. In this work, the objective was to determine the possible root cause of a fracture in a gear tooth, through tests such as chemical analysis performed via optical emission spectrometry by scintillation,
\end{abstract}




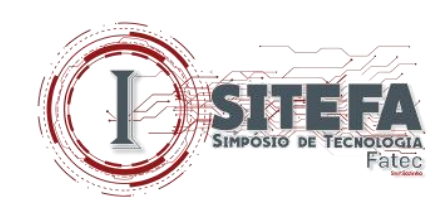

macrostructural analysis and microhardness profile. As a result, not only the characterization of the material, stress concentrators in the manufacturing process, but also the microhardness range between the surface of the material to the center by measurement in vickers.

Keywords: Fatigue. Gear Tooth. Failure Analysis. Toughness. Mechanical Properties.

\section{DOI:}

\section{INTRODUÇÃO}

Com o desenvolvimento de novas tecnologias, que buscam cada vez mais a otimização da relação custo/benefício para uma maior competitividade, grande ênfase tem sido dada na seleção adequada dos materiais e na análise/prevenção de falhas. Por exemplo, na indústria aeronáutica, as ligas de alumínio utilizadas para componentes de aviões devem ser leve, forte, e capaz de resistir a cargas mecânicas cíclicas durante um longo e previsível período de tempo. Já os aços utilizados para a construção de estruturas, tais como edifícios e pontes, devem ter resistência suficiente de modo que estas estruturas possam ser construídas sem comprometer a segurança. Da mesma forma, o desempenho de tacos de golfe, esquis e outros equipamentos de esporte depende não só da força e do peso dos materiais utilizados, mas também da sua capacidade de trabalhar sob um carregamento dinâmico, isto é, sob impacto. Para aplicações em que seja necessário o suporte de cargas, os materiais devem ser selecionados tomando-se por base suas propriedades mecânicas correspondentes às especificações de projeto e as condições de serviço exigidas do componente.

Falhas em serviço de componentes e estruturas têm acontecido cada vez mais em diversas indústrias, muitas vezes sem qualquer aviso. Algumas falhas podem ser triviais, enquanto outras podem ter consequências graves, resultando em fatalidades, lesões a pessoas, danos à propriedade, desligamento de uma planta inteira, perda de produção, problemas ecológicos (materiais perigosos), litígios caros e prolongados que afetam a credibilidade dos fabricantes e a confiabilidade de seus produtos, impactando fortemente sobre a sociedade e sua economia.

Para a compreensão das falhas e sua prevenção, existe a necessidade de aplicação de várias técnicas e conceitos da ciência e da tecnologia, sendo um assunto extremamente complexo e que envolve as áreas de mecânica, física, metalurgia, química e eletroquímica, 


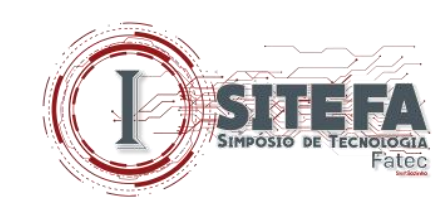

processos de fabricação, análise de tensão, análise de projeto e mecânica da fratura, dentre outras.

O intuito do presente trabalho é o de analisar a quebra de um dente de engrenagem, levando em consideração os diversos conceitos e técnicas para a correta identificação da causa raiz da falha, que ocorre pela ruptura no dente devido a causas prováveis tais como: sobrecarga; problemas na usinagem/retifica que proporcionam um concentrador de tensões; ruptura na raiz do dente por meio de uma força de flexão do torque motriz; pites/cavidades que geralmente acontece em materiais com ausência de tratamento térmico superficial; desgaste por adesão que é causado por uma lubrificação irregular aumentando assim os níveis de temperatura; desalinhamento do mancal/acoplamento/eixo; desgaste abrasivo que ocorre por lubrificante contaminado com partículas solidas; corrosão do dente de engrenagem devido a oxidação ou contaminação, etc.

\section{FUNDAMENTAÇÃO TEÓRICA}

Segundo Wulpi (1999), através da análise de falhas e da implementação de medidas preventivas, melhorias significativas na qualidade de produtos, sistemas e processos de fabricação, foram alcançadas. Isto requer não apenas uma compreensão do papel da análise de falhas, mas também uma avaliação da garantia de qualidade e das expectativas do usuário.

Em uma área que inicialmente ganhou proeminência global na década de 1980, corporações, fábricas, agências governamentais e outras organizações desenvolveram novos sistemas e processos de gestão destinados a melhorar a qualidade e a satisfação do cliente. Alguns desses sistemas incluem o Total Quality Management (TQM), a Melhoria Contínua (CI), e mais recentemente o Seis Sigma. Historicamente, essas iniciativas são baseadas nas filosofias dos visionários de qualidade W. Edwards Deming e Joseph Juran.

Em suas descrições mais básicas, TQM e CI representam o comprometimento organizacional completo com um sistema focado em "fazer a coisa certa na primeira vez" e não apenas atender, mas exceder os requisitos do cliente. Eles estão focados em melhorias de processo, geralmente em um ambiente de produção.

Devido a implantação da produção em série instituída por Ford, houve a necessidade de criar uma equipe de reparos imediatos para a não paralização dos ativos e perda de 


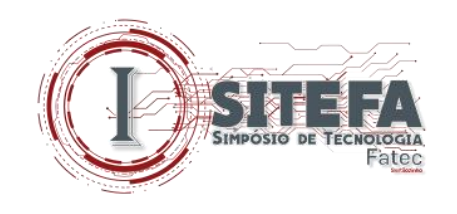

produtividade, a equipe usava como ferramenta de sua atividade principal a manutenção corretiva, que por sua vez não estava a satisfazer o mercado, pois o mesmo cada vez mais se tornava competitivo, do qual houve a necessidade de maior confiabilidade sobre os ativos, afim de promover segurança e durabilidade, surgiu então a equipe de manutenção, posteriormente engenharia de manutenção, que trabalha com enfoque na manutenção preventiva, preditiva e detectiva. Que não mais apenas se atentava a reparos comuns como também ao aprimoramento da eficácia em encontrar o motivo do defeito, que é por sua vez a causa raiz.

Com o avanço da tecnologia e a manufatura cada vez mais em alta, tem sido necessário a presença de ferramentas inovadoras de análise de falhas para melhor desempenho do processo objetivando a "quebra zero", sendo necessário avaliar a causa raiz da falha encontrada para dar início a solução de problemas, que por sua vez causa paradas inesperadas. Sendo assim é possível fazer um mapeamento com técnicos de manutenção juntamente com operadores, visando prolongar a vida útil dos ativos.

O Failure Mode and Effect Analysis (FMEA) é uma das ferramentas de análise de falhas que tem por objetivo prever e analisar uma falha ou um risco, num produto ou processo, através de perguntas provenientes de um questionário pré- estabelecido, que tem por objetivo ajudar na descoberta de qual ou quais foram a causa ou as causas, identificar corretamente o efeito ou os efeitos, sendo assim possível eliminar ou reduzir a chance de que ocorra novamente a mesma falha.

Semelhante ao FMEA, o Manutenção Centrada em Confiabilidade (MCC) também é uma ferramenta de análise de falhas, que consegue trabalhar de forma equilibrada os meios de manutenção, sejam eles a corretiva, a preventiva e a preditiva. O propósito desta ferramenta é a de promover a otimização da relação custo/benefício, tanto em horas de máquina parada como em manutenção excessiva, visando sempre a confiabilidade e a segurança, dispondo de um banco de dados previamente preenchido por manutenções anteriores, contando com a união de tecnólogos, engenheiros, operadores e técnicos de manutenção.

Segundo Becker e Shipley (2002), no sentido geral da palavra, uma falha é definida como um evento ou condição indesejável. Para fins de discussão relacionados à análise e prevenção de falhas, é um termo geral usado para sugerir que um componente é incapaz de 


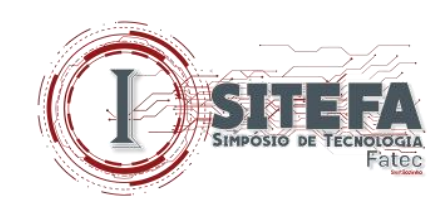

desempenhar adequadamente sua função pretendida. A definição de uma falha pode variar muito, de acordo com a função pretendida de um componente.

O termo "falha" é sinônimo de "defeito" no uso geral. No entanto, para um especialista em mecânica de fraturas, uma falha é uma descontinuidade, como uma trinca. Em algumas circunstâncias, quando a trinca é menor do que o tamanho crítico (ou seja, subcrítica), a trinca é benigna e, portanto, pode não ser considerada um defeito. Para o engenheiro de controle de qualidade, as falhas são características que são gerenciadas continuamente na linha de produção, já que cada produto modificado apresenta falhas, ou “desvios da perfeição". No chão de fábrica, essas falhas são medidas, comparadas com os limites preestabelecidos de aceitabilidade, e dispostas como aceitáveis ou rejeitáveis. Uma característica rejeitável é definida como um defeito.

Os três níveis de análise de causa raiz são raízes físicas, raízes humanas e raízes latentes. Raízes físicas, ou raízes dos problemas do equipamento, são onde muitas análises de falhas param. Essas raízes podem ser o resultado de uma investigação de laboratório ou análise de engenharia e, muitas vezes, são descobertas no nível de componente ou no nível de materiais. Raízes humanas (ou seja, questões de pessoas) envolvem fatores humanos que causaram o fracasso, sendo um exemplo um erro no julgamento humano. Raízes latentes nos levam às causas do erro humano e incluem raízes que são organizacionais ou processuais por natureza, bem como raízes ambientais ou outras que estão fora do domínio do controle (BECKER; SHIPLEY, 2002).

Como ferramenta primordial para o início do estudo e a análise de falhas tem-se o instrumento dos ensaios mecânicos, sejam eles os destrutivos (ensaio de impacto, ensaio de tração, ensaio de cisalhamento, ensaio de embutimento, ensaio de dureza) ou os nãodestrutivos (ensaio por radiografia, ensaio por ultrassom, ensaio por liquido penetrante, ensaio por partículas magnéticas, ensaio por inspeção visual), que propiciam a determinação das propriedades mecânicas do material ou componente. Geralmente esses ensaios são destrutivos, pois promovem a ruptura ou a inutilização do material. Existem ainda os ensaios chamados não-destrutivos, utilizados para determinação de algumas propriedades físicas do material, bem como para detecção de falhas internas no mesmo (SOUZA, 1982).

Um dos ensaios mais básico é o de Dureza, que consiste em uma medida da resistência de um material a uma deformação plástica localizada, isto é, consiste na impressão de uma 


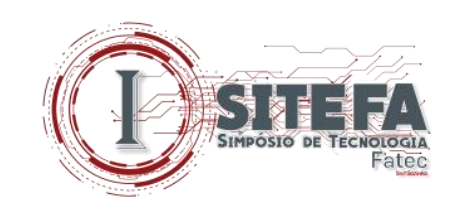

pequena marca na superfície da peça pela aplicação de pressão com uma ponta de penetração. A dureza é um conceito físico largamente utilizado nas suas diversas aplicações em todo o mundo (CALLISTER, 2008), sendo que sua medida é dada como função das características da marca de impressão e da carga aplicada em cada tipo de ensaio de dureza realizado (GARCIA; SPIM; SANTOS, 1999).

$\mathrm{Na}$ área mecânica, é importante distinguir os conceitos de endurecibilidade ou temperabilidade do conceito de dureza, a primeira é uma medida da resistência à deformação plástica, já a segunda é a maior ou menor facilidade com que se pode conseguir a dureza, ou o aumento desta (VAN VLACK, 2008).

Outro conceito muito importante é o de fadiga, fenômeno este observado pela primeira vez por volta de 1800, quando os eixos de um vagão ferroviário começaram a falhar após um pequeno período em serviço. Apesar de serem feitos de aço dúctil, os mesmos exibiam características de fraturas frágeis e repentinas. Rankine publicou um artigo em 1843, "As Causas da Ruptura Inesperada de Munhões de Eixos Ferroviários”, no qual dizia que o material havia "cristalizado" e se tornado frágil devido às tensões flutuantes (ABRAHÃO et al., 2008).

O desenvolvimento de trincas de fadiga dentro das bandas de escorregamento depende fundamentalmente do movimento das discordâncias. Uma vez iniciada a trinca, ela se propaga macroscopicamente e de uma maneira descontínua em um plano situado em ângulo reto com o plano de tensões principais atuantes no corpo de prova (SOUZA, 1982).

As falhas por fadiga sempre têm início com uma pequena trinca, que pode estar presente no material desde a sua manufatura ou desenvolver-se ao longo do tempo devido às deformações cíclicas ao redor das concentrações de tensões. Praticamente todas as partes de uma estrutura contêm descontinuidades, sejam microscópicas ou macroscópicas, introduzidas nos processos de fabricação ou de manufatura das mesmas. As trincas de fadiga geralmente têm início em um entalhe ou em outro elemento concentrador de tensão (ABRAHÃO et al., 2008).

Existem três estágios na falha por fadiga:

- $\quad$ início da trinca (pequena duração caso o material apresente concentrador de tensão);

- $\quad$ propagação da trinca (maior tempo de vida da peça); 


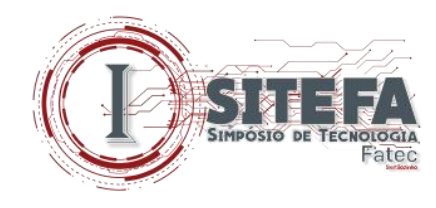

- $\quad$ ruptura repentina devido ao crescimento instável da trinca (instantâneo, sem aviso prévio).

Existe uma outra importante característica de fadiga, isto é, as chamadas "marcas de praia”. Assim como as estrias, as marcas de praia também são semicirculares, mas são, entretanto, visíveis a olho nu. As marcas de praia podem ser originadas através dos diferentes graus de oxidação produzidos nas sucessivas paradas para repouso do equipamento ou pela variação nas condições de carregamento. Estas marcas representam milhares ou mesmo milhões de ciclos e elas apontam para o local de início de propagação de trinca. A proporção entre a etapa de propagação e a ruptura final indicam o grau de sobrecarga da peça ou o coeficiente de segurança aplicado (SHIGLEY, 2005).

Há diversas técnicas para observar a estrutura dos aços e ferros fundidos em escala microscópica. Para um grande grupo de técnicas em que se observa a microestrutura através de seções, as técnicas de preparação de amostra são muito semelhantes (COLPAERT, 2008).

A microestrutura dos materiais (cristalinos) é, na maioria dos casos, constituída de fases cristalinas e de defeitos cristalinos tais como contornos de grãos, contornos de subgrãos, contornos de maclas, defeitos de empilhamento, interfaces, discordâncias e defeitos puntiformes. Muitas propriedades dos materiais, tais como limite de escoamento, limite de resistência, tenacidade à fratura, resistência ao desgaste e resistência à corrosão são fortemente dependentes da microestrutura.

Outras propriedades, tais como ponto de fusão, módulo de elasticidade, densidade e coeficiente de dilatação térmica, são fracamente dependentes da microestrutura. Estas propriedades são mais dependentes da distribuição eletrônica, do tipo de ligação química predominante e da estrutura cristalina. A caracterização da microestrutura dos materiais exige naturalmente a utilização de numerosas técnicas complementares de análise microestrutural tais como difração de raios $\mathrm{X}$, microscopia óptica, microscopia eletrônica de varredura, microscopia eletrônica de transmissão, microssonda eletrônica e numerosas técnicas indiretas (PADILHA, 1997).

Quanto a análise química dos aços, para a identificação dos elementos químicos presentes no material, é frequentemente realizada por espectrometria de emissão óptica, em que se mede simultaneamente a intensidade das várias linhas espectrais da luz emitida dos átomos que compõe a amostra, quando são excitados por uma fonte externa de energia. A 


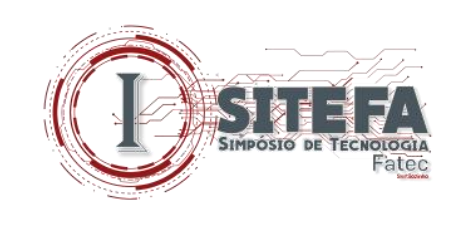

emissão da luz, em forma de radiação monocromática, é consequência do deslocamento de elétrons dos átomos de uma órbita à outra, com mudanças no seu estado de energia. Para cada elemento existem faixas espectrais características (HAYAKAWA; KAJITA; JESZENSKY, 2018). Alterações como corte, furação e esmerilhamento podem arruinar uma investigação se forem executadas prematuramente, sendo recomendado a proteção do local bem como das superfícies de fratura. Em geral, os testes destrutivos devem ser executados, de maneira geral, depois que todas as informações possíveis tenham sido estratificadas, a partir da peça na condição original, e após todas as características significativas terem sido explicitamente documentadas por registro fotográfico (WULPI, 1999).

Quanto aos tratamentos de superfície, para melhoria das propriedades e aumento da performance do componente, os aços utilizados, no tratamento termoquímico de cementação, por exemplo, devem aliar ao final do tratamento uma superfície dura com um núcleo tenaz. Os aços cementados geralmente são usados em engrenagens (dentes cementados), matrizes para estampagem, pinos móveis e eixos (COLPAERT, 2008).

De acordo com Chiaverini (1979), deve ser levado em conta dois fatores principais para a escolha do aço a ser cementado:

- $\quad$ o meio de resfriamento ao qual o aço será submetido após a cementação, para que ocorra a têmpera,

- $\quad$ e os níveis e os tipos de tensões que a peça estará sujeita.

Outros fatores determinantes para a escolha do aço a ser cementado, são os níveis e tipos de tensões que se desenvolvem após o tratamento térmico. Três variáveis devem ser consideradas, sendo elas a espessura da camada cementada, a característica microestrutural do núcleo e a zona de transição.

A camada cementada geralmente apresenta duas composições químicas distintas: hipereutetóides ou eutetóide (podendo ser um pouco hipoeutetóides). Alguns elementos de liga ajudam a aumentar o teor de carbono na superfície do aço, como o cromo e o molibdênio, formando carbonetos; outros elementos já atuam de forma contrária, eles ajudam a formar ferrita, por exemplo: o silício e o cobre. A temperatura e o tempo irão influenciar diretamente no tamanho da camada cementada e no gradiente de carbono contido na peça, pois esses dois fatores atuam diretamente na taxa de difusão do carbono. O núcleo do aço cementado deve ser tenaz, porém é recomendável que haja uma camada cementada com melhor tenacidade ao 


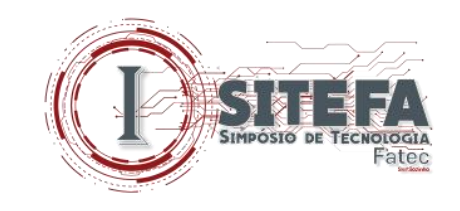

invés de controlar em excesso o aumento da tenacidade do núcleo, pois se houver uma trinca na camada cementada o núcleo tenaz não irá impedir o colapso da peça. A zona de transição entre a camada cementada e o núcleo da peça é de extrema importância. Ela deve ter uma diminuição gradual de dureza para que não ocorra o"lascamento" da superfície cementada. Um aumento da temperabilidade do aço favorece a formação de uma zona de transição gradual, sendo este motivo do uso de aços ligados para a cementação (CHIAVERINI, 1979).

\section{PROCEDIMENTOS METODOLÓGICOS}

O material e o método utilizados na pesquisa são apresentados nas subseções 3.1 e 3.2.

\subsection{Material}

Para a execução deste estudo, foi recebido para a análise de falhas um dente de engrenagem, como identificado na Figura 1, sem maiores informações a respeito das condições de operação bem como das especificações de projeto.

Figura 1 - Amostra recebida para ensaio/análise. (Vista superior).

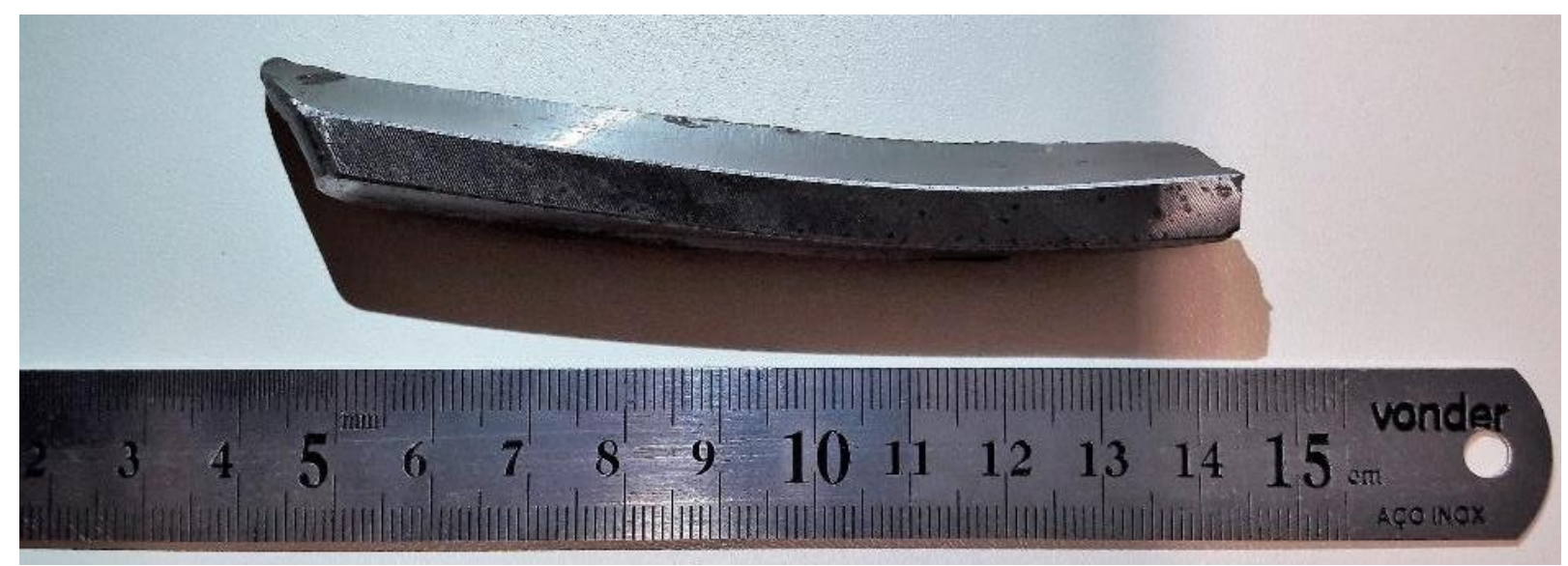

Fonte: os autores

\subsection{Método}

O quadro 1 apresenta a metodologia empregada para a execução dos ensaios e análises bem como as normas internacionais de referência. 
Quadro 1 - Metodologia empregada.

\begin{tabular}{|l|l|}
\hline Análise & \multicolumn{1}{|c|}{ Descrição } \\
\hline \multirow{3}{*}{ Análise Química } & $\begin{array}{l}\text { A análise química realizada via espectrometria de emissão óptica por } \\
\text { centelhamento, mede simultaneamente a intensidade das várias linhas } \\
\text { espectrais da luz emitida dos átomos que compõe a amostra, quando são } \\
\text { excitados por uma fonte externa de energia. }\end{array}$ \\
\hline \multirow{5}{*}{ Análise Macroestrutural } & $\begin{array}{l}\text { A análise macrográfica óptica é utilizada para visualização da superfície de } \\
\text { fratura e identificação de anomalias bem como de detalhes da geometria do } \\
\text { componente. }\end{array}$ \\
\hline Mureza e Perfil de & $\begin{array}{l}\text { Medições de dureza de acordo com as normas ASTM E18-11 e E140-07, na } \\
\text { escala Rockwell C, para as medições realizadas na superfície e no núcleo da } \\
\text { peça. } \\
\text { Medições de microdureza de acordo com a norma ASTM E384-10, na escala } \\
\text { Vickers, para as medições realizadas a partir da superfície e a cada 0,05mm, } \\
0,10 \text { mm, 0,20mm e 0,30mm, no sentido do centro do corpo de prova de } \\
\text { cementação. }\end{array}$ \\
\hline
\end{tabular}

Fonte: elaborado pelos autores

\section{RESULTADOS E DISCUSSÃO}

Esta seção apresenta os resultados das análises química, macroestrutural e de Dureza e Perfil de Microdureza.

\subsection{Análise Química}

A Tabela 1 apresenta o resultado da análise química, via espectrometria óptica, na região da superfície do dente de engrenagem. 
Tabela 1 - Resultado da análise química do dente da engrenagem; Superfície do dente.

\begin{tabular}{|c|c|c|c|}
\hline \multicolumn{3}{|c|}{ Especificação } & \multirow{2}{*}{$\begin{array}{c}\text { Amostra (s) } \\
\text { Dente de } \\
\text { engrenagem }\end{array}$} \\
\hline Elementos & Mín & Máx & \\
\hline $\mathrm{C}$ & 0,15 & 0,21 & 0,511 \\
\hline $\mathrm{Si}$ & - & 0,40 & 0,301 \\
\hline Mn & 0,50 & 0,90 & 0,503 \\
\hline $\mathrm{P}$ & - & 0,035 & $<0,0005$ \\
\hline$S$ & - & 0,035 & $<0,0005$ \\
\hline $\mathrm{Cr}$ & 1,50 & 1,80 & 1,66 \\
\hline Mo & 0,25 & 0,35 & 0,30 \\
\hline $\mathrm{Ni}$ & 1,40 & 1,70 & 1,63 \\
\hline $\mathrm{Al}$ & - & - & 0,025 \\
\hline $\mathrm{Co}$ & - & - & 0,023 \\
\hline $\mathrm{Cu}$ & - & - & 0,310 \\
\hline $\mathrm{Nb}$ & - & - & ND \\
\hline $\mathrm{Ti}$ & - & - & 0,002 \\
\hline V & - & - & 0,002 \\
\hline W & - & - & ND \\
\hline $\mathrm{Pb}$ & - & - & ND \\
\hline $\mathrm{Sn}$ & - & - & 0,060 \\
\hline As & - & - & 0,008 \\
\hline $\mathrm{Zr}$ & - & - & ND \\
\hline $\mathrm{Bi}$ & - & - & ND \\
\hline $\mathrm{Ca}$ & - & - & 0,002 \\
\hline $\mathrm{Ce}$ & - & - & ND \\
\hline B & - & - & ND \\
\hline $\mathrm{Zn}$ & - & - & 0,003 \\
\hline $\mathrm{La}$ & - & - & ND \\
\hline
\end{tabular}




\section{(1) SIIEE}

A Tabela 2 apresenta o resultado da análise química, via espectrometria óptica, na região do núcleo do dente de engrenagem.

Tabela 2 - Resultado da análise química do dente da engrenagem; núcleo do dente.

\begin{tabular}{|c|c|c|c|}
\hline \multicolumn{3}{|c|}{ Especificação } & \multirow{2}{*}{$\begin{array}{c}\text { Amostra (s) } \\
\text { Dente de engrenagem }\end{array}$} \\
\hline Elementos & Mín & Máx & \\
\hline $\mathrm{C}$ & 0,15 & 0,21 & 0,253 \\
\hline $\mathrm{Si}$ & - & 0,40 & 0,289 \\
\hline $\mathrm{Mn}$ & 0,50 & 0,90 & 0,460 \\
\hline $\mathrm{P}$ & - & 0,035 & $<0,0005$ \\
\hline$S$ & - & 0,035 & 0,0011 \\
\hline $\mathrm{Cr}$ & 1,50 & 1,80 & 1,57 \\
\hline Mo & 0,25 & 0,35 & 0,29 \\
\hline $\mathrm{Ni}$ & 1,40 & 1,70 & 1,61 \\
\hline $\mathrm{Al}$ & - & - & 0,019 \\
\hline $\mathrm{Co}$ & - & - & 0,026 \\
\hline $\mathrm{Cu}$ & - & - & 0,323 \\
\hline $\mathrm{Nb}$ & & - & ND \\
\hline $\mathrm{Ti}$ & & - & 0,001 \\
\hline V & & - & 0,001 \\
\hline $\mathrm{W}$ & & - & ND \\
\hline $\mathrm{Pb}$ & & - & 0,004 \\
\hline $\mathrm{Sn}$ & & - & 0,061 \\
\hline As & & - & 0,008 \\
\hline $\mathrm{Zr}$ & & - & ND \\
\hline $\mathrm{Bi}$ & & - & ND \\
\hline $\mathrm{Ca}$ & & - & 0,002 \\
\hline $\mathrm{Ce}$ & & - & ND \\
\hline B & & - & ND \\
\hline $\mathrm{Zn}$ & & - & 0,002 \\
\hline $\mathrm{La}$ & & - & ND \\
\hline
\end{tabular}

(* ND = Não Detectado) 


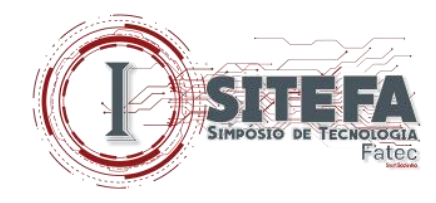

\subsection{Análise Macroestrutural}

A Figura 2a apresenta a macrografia do dente de engrenagem, vista da região superior, e a Figura 2 b mostra uma ampliação da mesma.

$\mathrm{Na}$ figura $2 \mathrm{a}$ vista superior do dente de engrenagem, foram identificadas ranhuras na crista do dente, o qual não foi possível identificar a olho nu, sendo assim na figura 2 (b) foi realizada a ampliação da região delimitada pelo círculo tracejado para melhor visualização.

Figura 2 - Macrografia óptica.

Figura 2a - Macrografia do dente de engrenagem

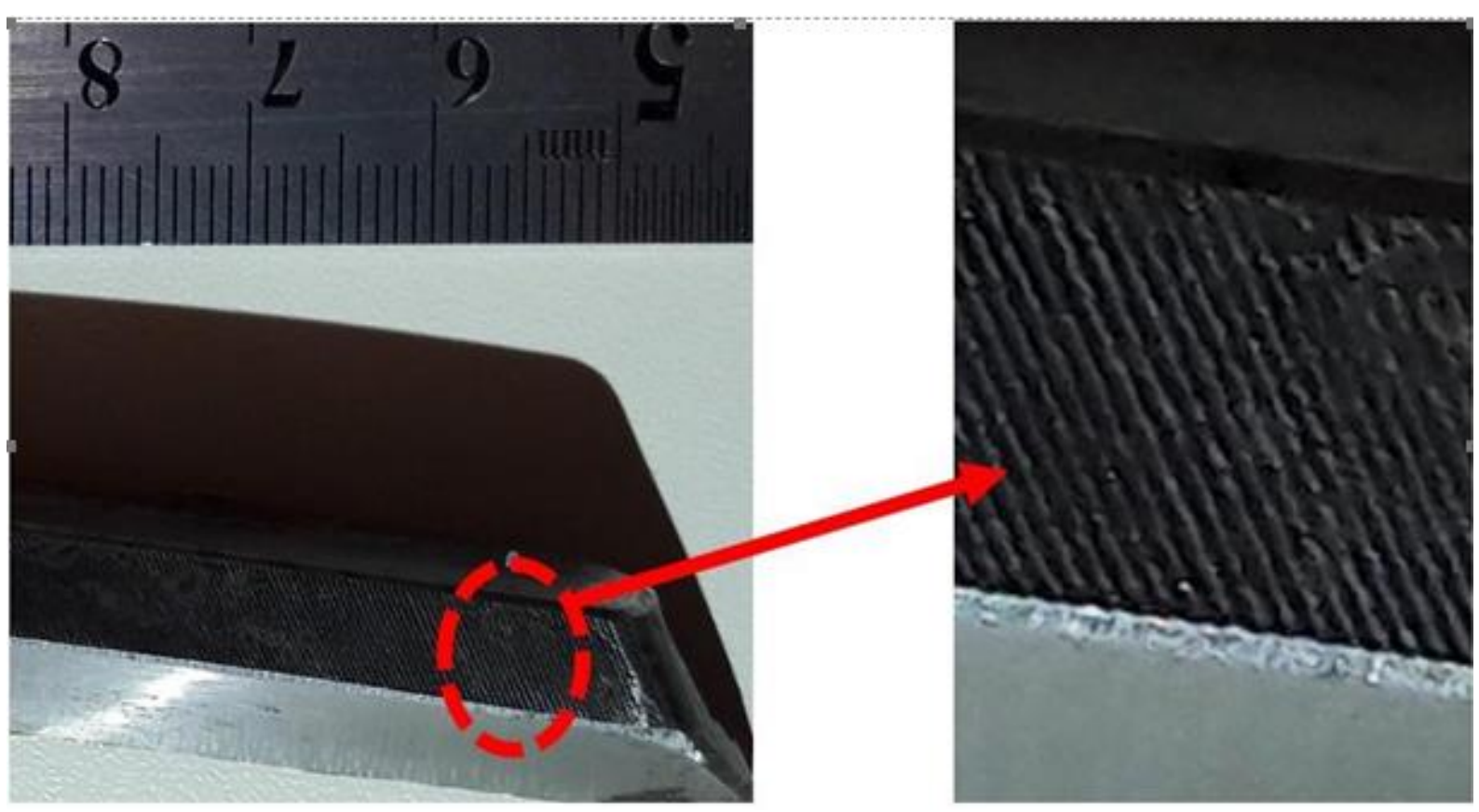

Fonte: fotografadas pelos autores durante a realização da pesquisa
Figura 2b - Ampliação da figura 2a 


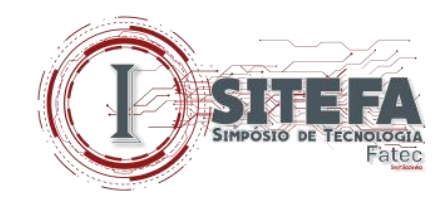

indicada pela seta, onde existe a presença de canto vivo que é um possível concentrador de tensões, como também se nota a falte de desgaste da mesma. $\mathrm{O}$ reagente utilizado foi nital a $10 \%$.

Figura 3 - Macrografia óptica do dente de engrenagem e indicação do corte de secção transversal, cuja macrografia está apresentada nas Figuras 3b e 3c.

Figura 3a - Vista

superior do dente de

engrenagem
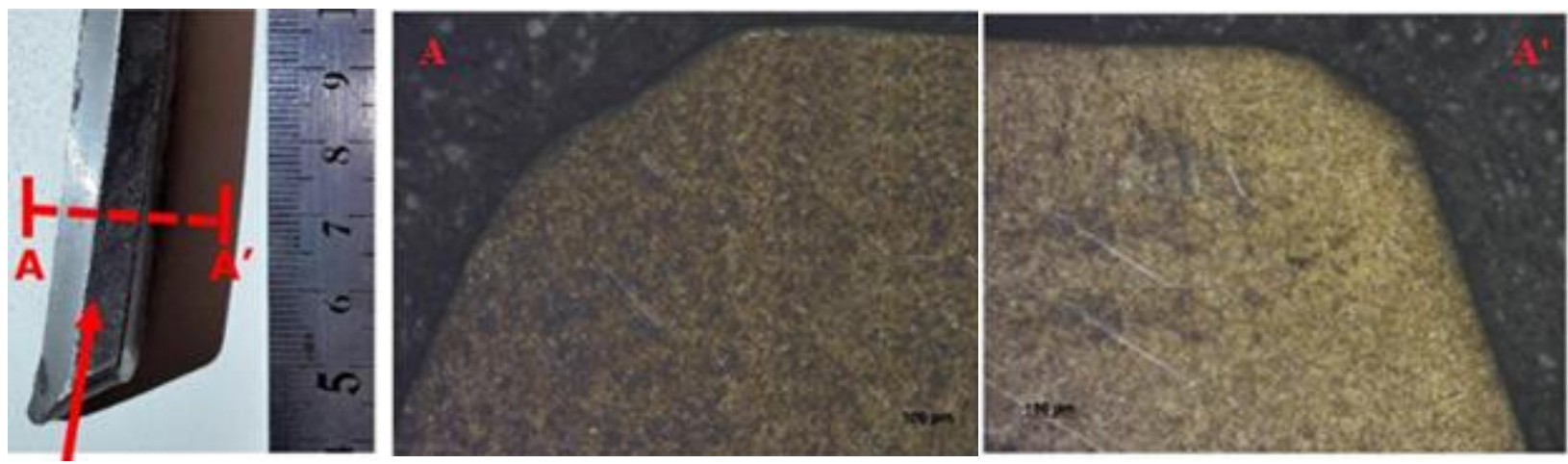

Fonte: fotografadas pelos autores durante a realização da pesquisa

\subsection{Perfil de Microdureza}

A Tabela 3 apresenta os resultados da medição do perfil de microdureza, realizada na escala Vickers. 


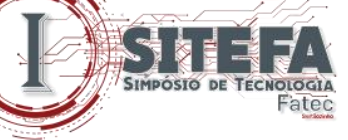

Tabela 3 - Ensaio de microdureza.

\begin{tabular}{|c|c|c|}
\hline Amostra & Distância da borda [mm] & Medidas [HV] \\
\hline & 0,05 & 573,3 \\
\hline & 0,10 & 588,7 \\
\hline & 0,20 & 568,3 \\
\hline & 0,30 & 602,0 \\
\hline & 0,40 & 592,6 \\
\hline & 0,50 & 583,5 \\
\hline & 0,60 & 546,5 \\
\hline & 0,70 & 587,3 \\
\hline & 0,80 & 579,6 \\
\hline & 0,90 & 567,0 \\
\hline & 1,00 & 553,6 \\
\hline & 1,10 & 562,1 \\
\hline & 1,20 & 541,9 \\
\hline & 1,30 & 520,5 \\
\hline & 1,40 & 517,3 \\
\hline & 1,50 & 508,7 \\
\hline \multirow[t]{17}{*}{ Dente de engrenagem } & 1,60 & 510,8 \\
\hline & 1,7 & 501,4 \\
\hline & 1,8 & 499,3 \\
\hline & 1,9 & 497,3 \\
\hline & 2,0 & 493,3 \\
\hline & 2,1 & 480,5 \\
\hline & 2,2 & 465,4 \\
\hline & 2,3 & 470,9 \\
\hline & 2,4 & 469,1 \\
\hline & 2,6 & 460,8 \\
\hline & 2,8 & 467,2 \\
\hline & 3,0 & 464,4 \\
\hline & 3,2 & 455,4 \\
\hline & 3,4 & 455,4 \\
\hline & 3,9 & 468,1 \\
\hline & 4,4 & 470,0 \\
\hline & 4,9 & 478,5 \\
\hline
\end{tabular}




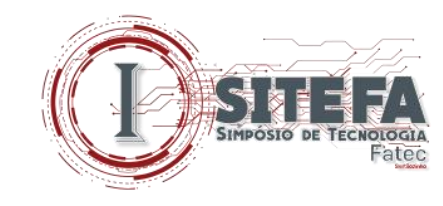

O gráfico 1 apresenta o perfil de microdureza Vickers no formato cartesiano. Os resultados encontrados no gráfico 1, onde no eixo x temos a distância da superfície ao núcleo da peça em milímetro, e no eixo y é dada a medida em vickers, onde as medidas encontradas na camada cementada que medi aproximadamente 1 milímetro de espessura, teve um resultado em média de 550 HV. Logo após houve uma queda linear em sentido ao núcleo.

\section{Gráfico 1 - Perfil de microdureza.}

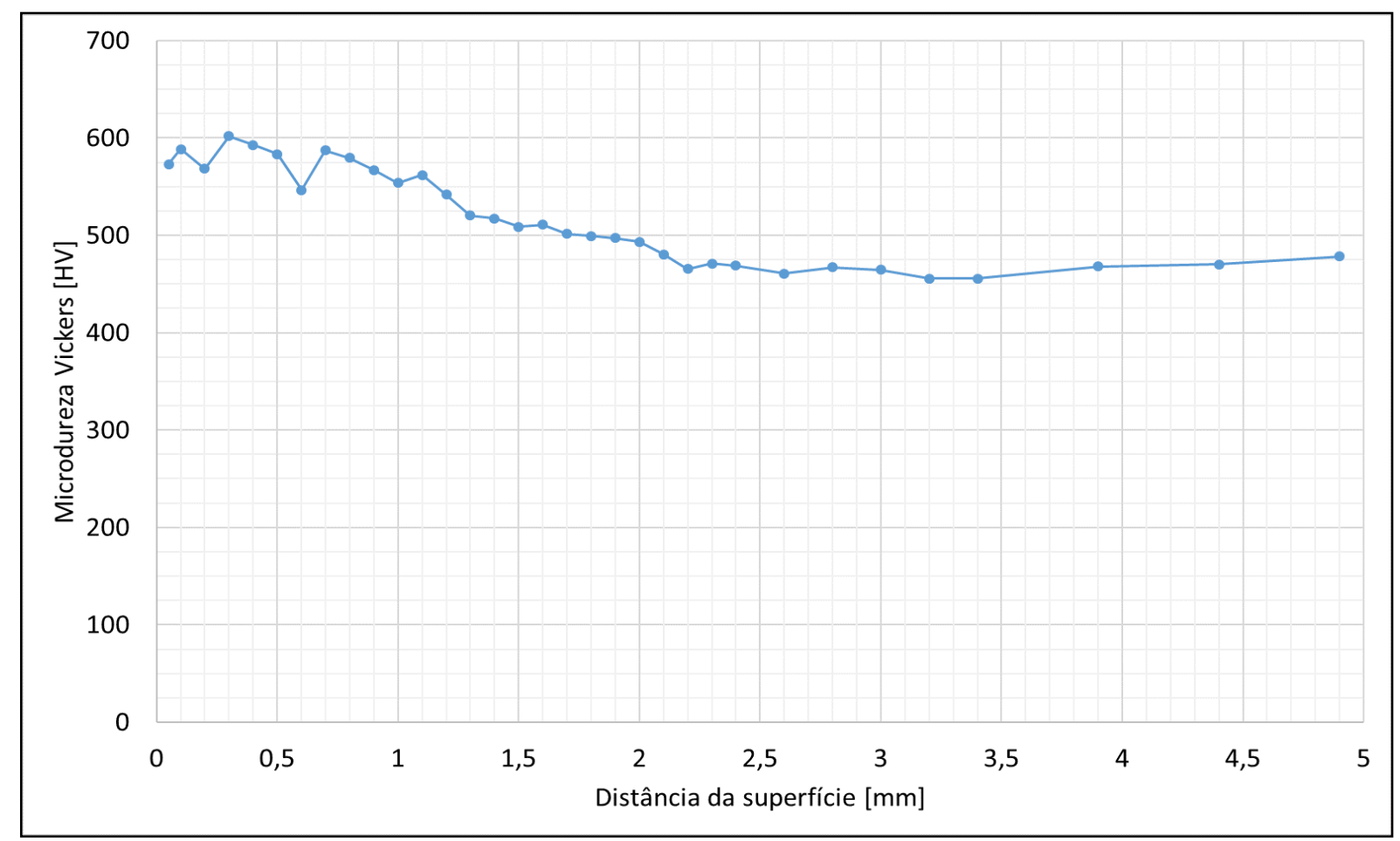

Fonte: elaborado pelos autores

\section{CONSIDERAÇÕES FINAIS}

Com relação a composição química (Tabela 2) do material do dente de engrenagem, pode-se concluir que se trata do aço 18CrNiMo7-6 DIN EN 10084. Além disto, observa-se, pela análise realizada na superfície do dente (Tabela 1), maiores teores do elemento carbono, evidenciando que o mesmo foi submetido a um processo de cementação.

Com relação as observações macroscópicas notam-se marcas na superfície superior do dente de engrenagem (Figuras 2a e 2b) e grande excentricidade (Figura 3b e 3c) nos raios de curvatura. Mesmo com a falta de especificações de projeto, pode-se concluir sobre prováveis 


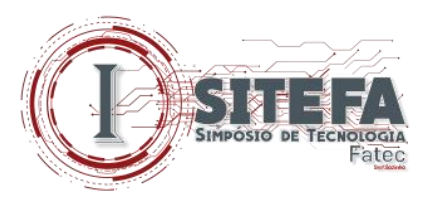

problemas durante a usinagem do componente. Este tipo de ranhura, que geralmente é deixada pela ferramenta utilizada na fase de fresamento, caracteriza-se como concentradores de tensão, o que pode facilitar a nucleação e posterior propagação de trincas por fadiga. $\mathrm{O}$ mesmo pode-se dizer a respeito da falta de suavização do raio de curvatura, a presença de quinas e cantos vivos são caracterizados como concentradores de tensão, facilitando a nucleação de trincas.

Quanto as medições do perfil de microdureza (Tabela 3 e Gráfico 1), observa-se que ocorreu o tratamento de cementação, fato este corroborado pela análise química da superfície que evidenciou maiores teores do elemento carbono. No entanto, mesmo com a falta de informações de projeto, conclui-se que o processo de cementação deve ser revisto, pois para este tipo de aplicação (dente de engrenagem) esperar-se-ia valores de microdureza, na superfície do dente, em torno de $870 \mathrm{HV}$ e diminuindo em direção ao centro/núcleo até o valor de 550HV evidenciando a profundidade da "camada cementada". No caso observado a microdureza permaneceu praticamente constante, em torno de $550 \mathrm{HV}$, ao longo da "camada cementada", sofrendo um pequeno decréscimo após $1 \mathrm{~mm}$ de profundidade. Baixos valores de dureza superficial aliados a concentradores de tensão são responsáveis pela nucleação de trincas em poucos ciclos de operação. Outro ponto a ser considerado é que a dureza está relacionada (diretamente proporcional) a resistência, assim, menores valores de dureza significam menores valores de (limite) resistência, o que pode levar a deformações plásticas quando submetidos a (picos de) carregamentos que excedam este limite. Como recomendações gerais aconselha-se melhorar o acabamento e aumentar a dureza superficial do componente.

\section{REFERÊNCIAS}

ABRAHÃO, R. R. R.; BITTENCOURT, C; TSURUTA, K. M.; RADE, R. S. L. Fadiga de Materiais, História da Falha por Fadiga. 2008. Disponível em: $<$ https://ss14799.websiteseguro.com/swge5/seg/cd2008/PDF/IC2008-0165.PDF>. Seminários de Iniciação Científica, UFU, 2008. Acesso em: 02 abr. 2018.

BECKER, W.T., SHIPLEY, R.J. Failure Analysis and Prevention. v. 11 of the ASM Handbook, 2002. 


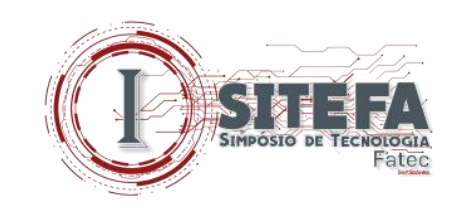

CALLISTER, W. D. Ciência e Engenharia de Materiais uma Introdução. 7. ed. Rio de Janeiro: Editora LTC, 2008.

CHIAVERINI, V. Aços e Ferros Fundidos. São Paulo: ABM, 1979.

COLPAERT, H. Metalografia dos Produtos Siderúrgicos Comuns. Revisão técnica André Luiz V. da Costa e Silva. 4. ed. São Paulo: Edgard Blucher, 2008.

GARCIA, Amauri; SPIM, Jaime Alvares; SANTOS, Carlos Alexandre dos. Ensaios dos materiais. Rio de Janeiro: LTC, 1999.

HAYAKAWA, M. O.; KAJITA, T.; JESZENSKY, G. Análise Química de Aços por Espectrometria Ótica. Disponível em:

<http://www.iaea.org/inis/collection/NCLCollectionStore/_Public/14/716/14716754.pdf.> Acesso em: 09 maio 2018.

PADILHA, Angelo Fernando. Materiais de Engenharia Microestrutura e Propriedades. São Paulo: Hemus SA. 1997.

SHIGLEY, J. E., Projeto de Engenharia Mecânica. Bookman, Michigan - USA, 2005.

SOUZA, Sérgio Augusto de. Ensaios Mecânicos de Materiais Metálicos - Fundamentos teóricos e práticos - 5. ed. São Paulo: Editora Edgard Blucher, 1982.

VAN VLACK, L. H. Princípios de Ciência e Tecnologia dos Materiais. 4. ed. Rio de Janeiro: Edgar Blucher, 2008.

WULPI, Donald J.. Understanding How Components Fail, ASM International, Materials Park, Ohio, USA, 1999. 